\title{
A top-down approach to understand the effect of vegetation changes on stream salinity
}

\author{
$\underline{\text { N.M. Malana }}{ }^{\text {a }}$, J. Costelloe ${ }^{\text {a }}$ and H.M. Malano ${ }^{\text {a }}$ \\ ${ }^{a}$ Department of Infrastructure Engineering, The University of Melbourne, Victoria 3010 Australia. \\ Email: m.malana@pgrad.unimelb.edu.au
}

\begin{abstract}
Large scale clearing of native forests for agriculture modifies the patterns of rainfall partitioning into evapotranspiration, runoff and infiltration. As deep rooted trees have higher evapotranspiration rates compared with shallow rooted crops for a given amount of rainfall, removal of native trees results in an increased recharge. This can mobilize salts stored in the unsaturated zone and groundwater. The discharge of salts from catchments causes the salinisation of water and land resources in sub-humid to semi-arid regions. In addition to causing significant loss to economy, the salinity issue is a serious threat to the environmental sustainability.

Stream salinity being a function of climate, physical characteristics of catchments and land cover, is highly variable in space and time. This variability can be explained on the basis of catchment scale data on climate, catchment attributes and landuse. However, the limitations of data availability require simpler approaches. The aim of this paper is, therefore, to demonstrate the use of readily available catchment-scale data and an annual evapotranspiration model in explaining the variability in stream salinity due to vegetation changes in a sub-humid environment.
\end{abstract}

We use a Budyko-type, an annual evapotranspiration model (Zhang et al. 2004) to understand the effects of vegetation changes on stream salinity. Catchment-scale observed data on climate (mean annual rainfall, actual evapotranspiration, and potential evapotranspiration) and time series of streamflow and salinity from 78 catchments across Victoria, Australia, were used in the analysis. Physical topographic characteristics of the study catchments were derived with the help of a digital elevation model of the area. Spatial information on vegetation, landuse, geology, and soils were obtained from digital maps of these variables. Groundwater salinity was derived from the interpolated surface of salinity data of groundwater bores in the region. The change in the native forest cover was estimated from the native vegetation maps of pre-European settlement (1788) and post-European settlement (1988). Statistical methods, including correlation analysis and ordinary least square regression were used in the analysis.

Based on catchment scale observed data and an annual evapotranspiration model (Zhang et al. 2004), it is shown that low flow salinity in our study catchments is highly associated with the evapotranspiration efficiency, fraction of catchment having flatter slopes, and the index of wetness. The analysis for our study region reveals that the catchments having evapotranspiration efficiencies between 0.5-0.6 and catchment parameter ' $w$ ' (Zhang et al. 2004) less than 1.46, can have saline low flow. These catchments are characterised with less forest cover, greater fraction of area having flatter slopes and dryland pasture and fall in the medium rainfall zone $(500-850 \mathrm{~mm}$ per year). Correlation analysis shows that low flow salinity is highly associated with evapotranspiration efficiency, index of wetness, catchment fraction having flatter slopes, area under native forests and dryland pasture. An ordinary least squares regression model for low flow salinity identified catchment parameter ' $\mathrm{w}$ ' and catchment fraction having $2 \%$ to $4 \%$ slopes and index of wetness as the explanatory variables. We expect that improvement in the model could be achieved by considering other alternatives, such as robust and spatially weighted regression and principal component analysis.

Key words: Landuse change, low flow salinity, annual evapotranspiration, Budyko 


\section{INTRODUCTION}

Large scale clearing of native deep-rooted vegetations for agriculture modifies the hydrologic balance due to changes in evapotranspiration (Ghassemi et al. 1995). Changes in hydrological balances are the main factor in mobilising large amounts of salts stored in groundwater and soil water (Herczeg et al. 2001). In order to understand the effect of land-use change on salinity processes at a catchment scale, it is important to partition rainfall into evaporation, runoff and recharge (Dawes et al. 2004). Salinity problems on a regional scale depend on changes in recharge brought by changes in land-use (ibid).

Spatial variability in stream salinity is a function of climate, topography and vegetation (van Dijk et al. 2008). Davey et al. (2006) reported that flatter areas ( $<2$ degrees slope) overlain by saline soils and rainfall between $500-850 \mathrm{~mm} /$ year are vulnerable to salinisation. They postulated that in drier areas (rainfall $<500$ $\mathrm{mm} /$ year), water is not available in sufficient quantity to mobilize salts while in wetter areas (rainfall $>850$ $\mathrm{mm} /$ year) salts are leached out of soils by rain water.

Zhang et al. (2004) explained that mean annual evapotranspiration from a catchment depends on the climatic variables and catchment attributes such as forest cover, plant available water storage capacity and topography. They used a rational function approach for estimating mean annual evapotranspiration that incorporates the net effect of climate and catchment characteristics. The model assumes that for a given precipitation, the rate of change in catchment evapotranspiration with respect to potential evapotranspiration increases with residual precipitation $(\mathrm{P}-\mathrm{E})$ but decreases with potential evapotranspiration $\left(\mathrm{E}_{\mathrm{o}}\right)$ (Zhang et al. 2004), mathematically:

$$
\frac{E}{E_{o}}=1+\frac{P}{E_{o}}-\left[1+\left(\frac{P}{E_{o}}\right)^{w}\right]^{1 / w}
$$

Where $\mathrm{E}, \mathrm{E}_{\mathrm{o}}$ and $\mathrm{P}$ are mean annual evapotranspiration, annual potential evapotranspiration and annual precipitation respectively. ' $w$ ' is a catchment parameter, assumed to represent the combined effect of climate and catchment characteristics such as vegetation cover, soil properties and topography (ibid). Zhang et al. (2004) showed that the effect of parameter ' $w$ ' on the evapotranspiration ratio (E/P) is insignificant under very dry or very wet condition except for $w<1.5$, as precipitation and available energy control evapotranspiration under these two extreme conditions. Smaller values of ' $w$ ' are associated with catchments having climatic or catchment attributes that support higher runoff and lower evapotranspiration ratios (E/P) (ibid). The sensitivity of evapotranspiration ratio $(\mathrm{E} / \mathrm{P})$ to parameter ' $w$ ' is maximised when the index of dryness $\left(E_{0} / P\right)$ is close to 1 (Zhang et al. 2004). Similarly, Zhang et al. (1999) pointed out that the maximum difference in the evapotranspiration ratio $(\mathrm{E} / \mathrm{P})$ between forest trees and herbaceous plants takes place when the index of dryness is around 1 (i.e. $\mathrm{E}_{\mathrm{o}} / \mathrm{P}=1$ ). Under such conditions, trees are able to extract water from a greater depth compared to herbaceous plants (ibid).

The total annual evapotranspiration from a forested catchment is greater than for non-forested catchment for a given amount of annual rainfall (Zhang et al. 1999). Zhang et al. (1999) presented a simple model for estimating annual evapotranspiration from a catchment based on mean annual rainfall and fraction of forest cover. This model can be used to assess the effect of changes in forest cover on catchment water balance. The model by Zhang et al. (1999) is given as follows:

$$
E T=\left[f \frac{1+2 \times \frac{1410}{P}}{1+2 \times \frac{1410}{P}+\frac{P}{1410}}+(1-f) \frac{1+0.5 \times \frac{1100}{P}}{1+0.5 \times \frac{1100}{P}+\frac{P}{1100}}\right] P
$$

Where, 'ET' is the annual evapotranspiration, ' $\mathrm{f}$ ' is the fraction of forest cover and ' $\mathrm{P}$ ' is catchment annual rainfall.

The main objective of this paper is to understand the effect of vegetation changes on low flow salinity in semi-arid to sub-humid regions. The catchment scale observed data on climate, catchment attributes and landuse were analysed to investigate spatial variability in low flow salinity. The catchment scale evapotranspiration models (Zhang et al. 1999 and Zhang et al. 2004) were used to assess the effect of vegetation changes on low flow salinity. An ordinary least square model is developed to predict low flow salinity in the study catchments. 


\section{METHODS}

The data used in the analysis is summarised in Table 1. The observed data on streamflow and salinity, climate, vegetation, geology, soils, catchment physical characteristics, and groundwater salinity were analysed from 78 catchments across Victoria, Australia. These catchments are from 17 river basins draining on either side of the Great Dividing Range. Time series of streamflows were analysed for quantifying the variability in streamflows, flow duration curves and baseflow index. Baseflow index was estimated by using the Chapman and Maxwell method (Grayson et al. 1996). Stream salinity data comprised primarily of mostly monthly observed values of stream salinity. The $10^{\text {th }}, 50^{\text {th }}$ and $90^{\text {th }}$ percentiles of stream salinity were then derived. Time series of streamflow and salinity covered different time periods and durations for different study catchments. The observed streamflow data was not available for about $1 / 6^{\text {th }}$ of the study catchments. These were infilled by computed (modelled) streamflow for these catchments (Table 1).

The study catchments were delineated with the help of a $90 \mathrm{~m}$ resolution digital elevation model (DEM) (Jarvis et al. 2008). The size of catchments varies from $32 \mathrm{~km}^{2}$ to $6240 \mathrm{~km}^{2}$. There are no large dams in the study catchments. Terrain attributes were derived from the DEM, such as elevation, relief, aspect, length of streams, drainage index, slope index, area fractions with different slopes (up to $2 \%, 2 \%-4 \%$ and $4 \%-7 \%$ ), stream order (Strahler), and stream bifurcation ratio. The catchment scale variability in the climate (mean annual rainfall, actual evapotranspiration, and potential evapotranspiration), soils, geology and land-use attributes were analysed with the help of digital maps.

Groundwater salinity was analysed from the time-series of 10,000 bores in the region. An interpolated surface of mean salinity values of these groundwater bores was generated in ArcGIS by using the inverse distance method. The catchment polygons and ArcGIS 'intersect' tool was used to obtain the mean groundwater salinity values. Similarly, the change in the native forest cover was estimated from the native vegetation maps of pre-European settlement (1788) and post-European settlement (1988). Statistical techniques such as the correlation analysis, rank and percentiles, linear regression were used for the analysis.

Table 1. Data sources

\begin{tabular}{|c|c|}
\hline Data set & Source \\
\hline Average annual rainfall & Bureau of Meteorology, Australia. (data period: 1961-1990) \\
\hline $\begin{array}{l}\text { Average annual potential } \\
\text { evapotranspiration }\end{array}$ & Bureau of Meteorology, Australia. (data period: 1961-1990) \\
\hline Digital elevation model $(90 \mathrm{~m})$ & $\begin{array}{l}\text { Jarvis A., Reuter, H.I., Nelson, A., and Guevara, E. (2008). Hole-filled seamless SRTM data V4, } \\
\text { International Centre for Tropical Agriculture (CIAT), <http://srtm.csi.cgiar.org.> }\end{array}$ \\
\hline Land use & Department of Sustainability and Environment, Victoria, Australia. \\
\hline Geology & $\begin{array}{l}\text { Raymond, O.L., Liu, S.F., Kilgour, P., Retter, A.J., Connolly, D.P. (2007). Surface Geology of } \\
\text { Australia 1:1,000,000 scale, Victoria - 3rd edition [Digital Dataset], Canberra: Geoscience Australia. } \\
\text { <http://www.ga.gov.au> }\end{array}$ \\
\hline Groundwater salinity & $\begin{array}{l}\text { Peterson, T. and Wealands, S. (2011). Groundwater Database (Version 1.11), Civil and } \\
\text { Environmental Engineering Department, The University of Melbourne, Victoria, Australia }\end{array}$ \\
\hline $\begin{array}{l}\text { Time series of observed and } \\
\text { computed streamflow and } \\
\text { salinity }\end{array}$ & $\begin{array}{l}\text { Department of Sustainability and Environment, Victoria, Australia. } \\
<\text { http://www.vicwaterdata.net/vicwaterdata }>\end{array}$ \\
\hline Vegetation cover & $\begin{array}{l}\text { Vegetation - Pre-European Settlement (1788) 1:5 million scale map, Geoscience Australia. } \\
\text { Vegetation - Post-European Settlement (1988), 1:5 million scale map, Geoscience Australia. } \\
\text { <http://www.ga.gov.au> }\end{array}$ \\
\hline
\end{tabular}

\section{RESULTS OF ANALYSIS}

\subsection{Catchment scale evapotranspiration and low flow salinity}

Based on the vegetation map of 1988, annual evapotranspiration for all study catchments was estimated by using equation (2). These estimated evapotranspiration values were then used in equation (1) for determining the catchment parameter ' $\mathrm{w}$ ' and evapotranspiration ratio (E/P) for each catchment. As the effects of forest clearing are more pronounced on low flow salinity, we used low flow salinity $\left(\mathrm{C}_{90}\right)$ as the relevant measure of stream salinity for this paper. The low flow salinity $\left(\mathrm{C}_{90}\right)$ is the salt concentration in streamflow not exceeded 90 percent of time.

Correlation between low flow salinity $\left(\mathrm{C}_{90}\right)$ and catchment evapotranspiration efficiency $\left(\mathrm{E} / \mathrm{E}_{\mathrm{o}}\right)$, catchment parameter ' $\mathrm{w}$ ', and index of wetness $\left(\mathrm{P} / \mathrm{E}_{\mathrm{o}}\right)$ is shown in figures 1 to 3 . Figure 4 shows correlation between evapotranspiration efficiency $\left(\mathrm{E} / \mathrm{E}_{\mathrm{o}}\right)$ and fraction of catchment forest cover. Each dot in the plots represents one catchment. 
Malana et al., A top-down approach to understand the effect of vegetation changes on stream salinity

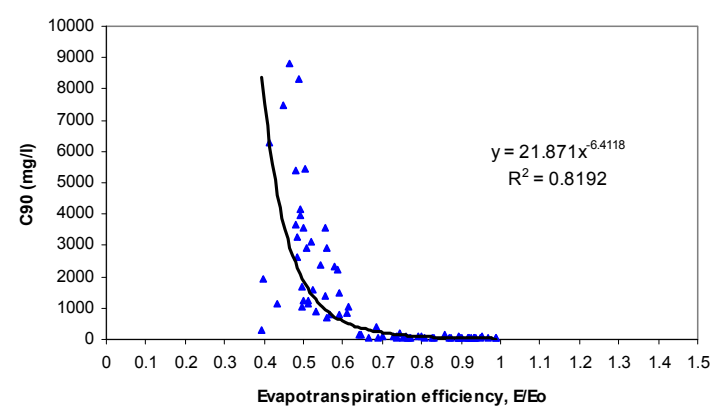

Figure 1. Correlation between evapotranspiration efficiency $\mathrm{E} / \mathrm{E}_{\mathrm{o}}$ and $\mathrm{C}_{90}$.

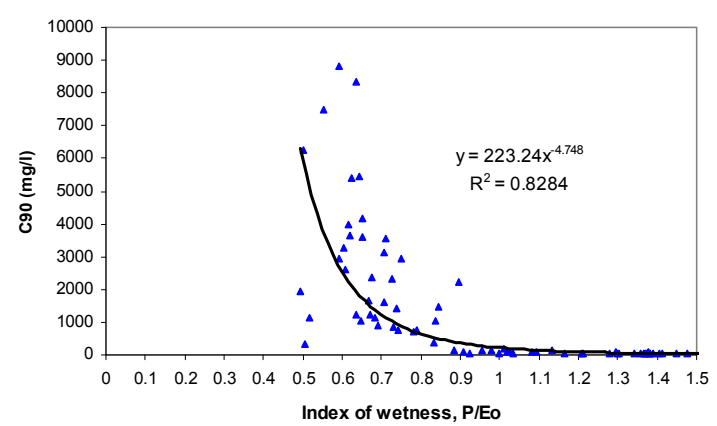

Figure 3. Correlation between index of wetness $\left(\mathrm{P} / \mathrm{E}_{\mathrm{o}}\right)$ and $\mathrm{C}_{90}$.

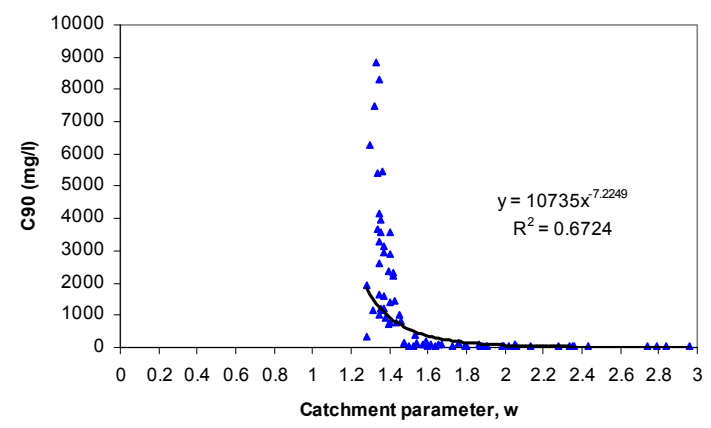

Figure 2. Correlation between catchment parameter 'w' and $\mathrm{C}_{90}$.

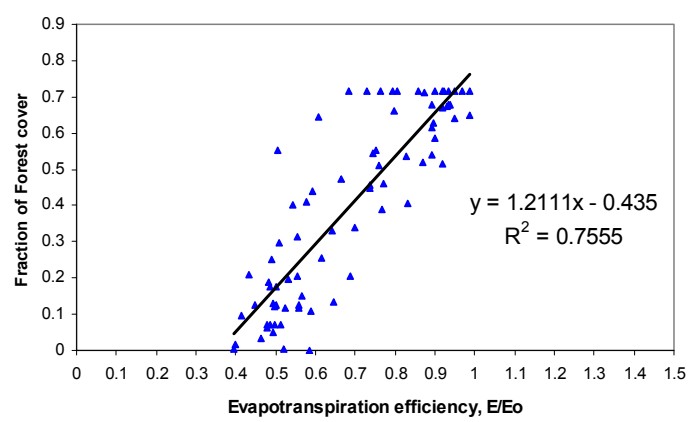

Figure 4. Correlation between evapotranspiration efficiency $\left(\mathrm{E} / \mathrm{E}_{\mathrm{o}}\right)$ and fraction of forest cover.

Table 2. Correlation of variables with low flow salinity $\left(\mathrm{C}_{90}\right)$

\begin{tabular}{|c|c|c|c|c|c|c|c|c|c|c|c|c|}
\hline Variable & $C_{90}$ & $E / E_{o}$ & $E / P$ & $P / E_{o}$ & $w$ & $m A R$ & $S L 1$ & $S L 2$ & M_sl & M_elev & $D L P$ & $n V e g$ \\
\hline $\mathrm{C}_{90}$ & 1.00 & & & & & & & & & & & \\
\hline$E / E_{o}$ & -0.66 & 1.00 & & & & & & & & & & \\
\hline$E / P$ & 0.53 & -0.77 & 1.00 & & & & & & & & & \\
\hline $\mathrm{P} / \mathrm{E}_{\mathrm{o}}$ & -0.63 & 0.98 & -0.87 & 1.00 & & & & & & & & \\
\hline w & -0.51 & 0.91 & -0.74 & 0.92 & 1.00 & & & & & & & \\
\hline mAR & -0.64 & 0.97 & -0.89 & 1.00 & 0.91 & 1.00 & & & & & & \\
\hline SL1 & 0.63 & -0.75 & 0.53 & -0.71 & -0.62 & -0.71 & 1.00 & & & & & \\
\hline SL2 & 0.68 & -0.90 & 0.69 & -0.87 & -0.77 & -0.88 & 0.81 & 1.00 & & & & \\
\hline M_sl & -0.57 & 0.85 & -0.73 & 0.86 & 0.78 & 0.88 & -0.73 & -0.89 & 1.00 & & & \\
\hline M_elev & -0.57 & 0.86 & -0.75 & 0.88 & 0.80 & 0.88 & -0.71 & -0.82 & 0.82 & 1.00 & & \\
\hline DLP & 0.56 & -0.77 & 0.40 & -0.72 & -0.71 & -0.72 & 0.52 & 0.73 & -0.74 & -0.65 & 1.00 & \\
\hline nVeg & -0.62 & 0.86 & -0.39 & 0.77 & 0.73 & 0.76 & -0.73 & -0.81 & 0.74 & 0.70 & -0.84 & 1.00 \\
\hline
\end{tabular}

Where, 'mAR' stands for mean annual rainfall, 'SL1' catchment fraction having up to $2 \%$ slope, 'SL2' Catchment fraction having slope $2 \%-4 \%$, 'M_sl' mean slope, 'M_elev' mean elevation, 'DLP' catchment fraction under dryland pasture, and 'nVeg' stands for catchment fraction of native forests. 


\subsection{Ordinary least square regression model for low flow salinity}

A correlation analysis was carried out to examine the association of low flow salinity $\left(\mathrm{C}_{90}\right)$ with a number of variables and indices related to climate, catchment characteristics and landuse. Table 2 shows correlation of variables with the low flow salinity. The variables were selected based on their correlation with low flow salinity $\left(\mathrm{C}_{90}\right)$ having correlation coefficients greater than 0.5 .

The low flow salinity $\left(\mathrm{C}_{90}\right)$ in the region can be predicted with the help of key variables that are closely associated with C90. However, due to covariance between the variables, it becomes difficult to identify the explanatory variables for low flow salinity $\left(\mathrm{C}_{90}\right)$ from the correlation coefficients (Table 2). We applied an ordinary least square regression to all variables shown in Tabel 2 to identify the explanatory variables for $\mathrm{C}_{90}$. The functional form between the explanatory variable and $\mathrm{C}_{90}$ was kept the same as found in the correlation plots (see Figure 1-3). The correlation of 'SL1', catchment fraction having up to $2 \%$ slope with $\mathrm{C}_{90}$ had no definite pattern, while 'SL2', catchment fraction having $2 \%$ to $4 \%$ slope was an exponential fit $\left(\mathrm{R}^{2}=0.78\right)$. The use of least square regression identified the best combination of variables that could explain variability in $\mathrm{C}_{90}$. It also optimized parameters of the variables. The catchment parameter ' $\mathrm{w}$ ', catchment fraction having slope up to $2 \%-4 \%$ (SL2), and index of wetness $\left(\mathrm{P} / \mathrm{E}_{\mathrm{o}}\right)$ were identified as the explanatory

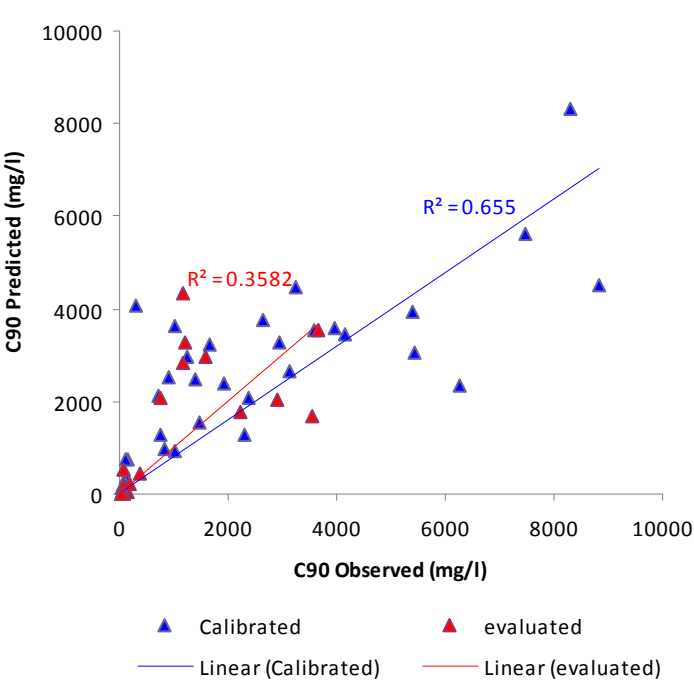

Figure 5. Comparison of observed and predicted $\mathrm{C}_{90}$ values. variables for $\mathrm{C}_{90}$ for the study catchments. The least squares regression model calibrated for 58 catchments is as follows:

$$
C_{90}=518278.02(w)^{-17.144}+5.3(e)^{0.179 \times S L 2}-0.155 \times 10^{-5}\left(\frac{P}{E_{o}}\right)^{-31.632}
$$

The study catchments were divided into two groups, 58 for calibration and 20 catchments for evaluation of the regression model (equation 3). As the study catchments represent 17 river basins from the region, the same variability was maintained in both the calibration as well as evaluation datasets. The calibrated regression model was applied to the 20 catchments for evaluation of the model. A comparison of observed and modelled $\mathrm{C}_{90}$ values is shown in Figure 5, for both the calibration and evaluation datasets.

\section{DISCUSSION AND CONCLUSION}

The use of catchment scale evapotranspiration models (equation 1 and 2) gives useful information on the effect of vegetation changes on low flow salinity $\left(C_{90}\right)$. Evapotranspiration efficiency $\left(E / E_{0}\right)$ is negatively correlated with low flow salinity (Figure 1, Table 2). A decrease in the evapotranspiration efficiency below the critical value of 0.6 shows a rising trend in low flow salinity. High low flow salinity values occur for the evapotranspiration efficiency values between 0.5 and 0.6 . The 0.5 to 0.6 range of evapotranspiration efficiency represent catchments with the medium rainfall zone $(500-850 \mathrm{~mm})$. Whereas, evapotranspiration efficiency values below 0.5 represent catchments with low annual rainfall and high annual potential evapotranspiration. Figure 4 shows that evapotranspiration efficiency significantly associated with the forest cover. Similarly, low flow salinity is also correlated with catchment parameter 'w'. However, variability of catchment parameter considerably reduces around 1.4. Based on the observed data, it was noted that catchments can be divided two main groups on the basis of catchment parameter ' $w$ '. One group having saline low flows and the other with less saline low flows. The low flow salinity $\left(\mathrm{C}_{90}\right)$ for the saline low flows ranges between $700 \mathrm{mg} / \mathrm{l}$ to $8832 \mathrm{mg} / \mathrm{l}$ and for the less saline between $29.44 \mathrm{mg} / \mathrm{l}$ to $390 \mathrm{mg} / \mathrm{l}$. Out of the 78 study catchments, 36 catchment have saline low flows with the catchment parameter ' $\mathrm{w}$ ' ranging from 1.27 to 1.45 and 42 catchments have less saline low flows with the catchment parameter ' $w$ ' ranging from 1.47 to 
2.9. It was noted that saline low-flow catchments had less forest cover, greater fraction of area having flatter slopes and dryland pasture and fall in the medium rainfall zone (500-850mm per year) (Davey et al. 2006).

Index of wetness $\left(\mathrm{P} / \mathrm{E}_{\mathrm{o}}\right)$ also shows close association with low flow salinity $\left(\mathrm{C}_{90}\right)$, especially in the range of 0.55 to 0.75 (Figure 3, Table 2). In this range, index of wetness $\left(\mathrm{P} / \mathrm{E}_{\mathrm{o}}\right)$ coincides with the medium rainfall zone (500-850mm). Correlation analysis (Table 2) shows that low flow salinity is closely associated with climate variables, catchment physical attributes and landuse variables (van Dijk et al. 2008). However, variables related to groundwater salinity and catchment geology were not found to be closely correlated with the low flow salinity in our study catchments. It was noted that the density of bores with groundwater salinity data and the catchment polygons were not overlapping spatially.

In order to develop a simple model, an ordinary least squares regression model for low flow salinity $\left(\mathrm{C}_{90}\right)$ identified the catchment parameter ' $\mathrm{w}$ ', catchment fraction having slope $2 \%-4 \%$ and index of wetness $\left(\mathrm{P} / \mathrm{E}_{\mathrm{o}}\right)$ as the key variables for the study catchments. The model consisted of nine parameters, 3 for variable coefficients and 2 parameters with the each variable in the model. As the parameters were optimized, the model does not present a unique solution and affects of local minima cannot be ignored. However, a better prediction model could be developed by adopting other alternatives, such as robust regression, spatially weighted regression and the principal component analysis. It is noted that the use of better explanatory variables and applying the model to a group of homogeneous catchments may improve model prediction. A strong covariance between different variables was noted (Table 2). This means that a number of variables provide similar type of information about a catchment. This is on-going study and therefore, uncertainty in the input data was not considered at this stage. The existence of covariance in the data and lack of uncertainty analysis on the input variables can be the likely cause of modest results from the regression model (equation 3).

The findings in this paper are in agreement with the previous studies, that large scale clearing of native deeprooted vegetations for agriculture modified the hydrologic balance due to changes in evapotranspiration and resulted in salinisation of land and water (Ghassemi et al. 1995, Zhang et al. 1999). This paper demonstrates that catchments characterized with saline low flows can be identified with the help of simple catchment scale evapotranspiration models and long term annual climate data.

\section{ACKNOWLEDGEMENTS}

N.M. Malana would like to thank Andrew Western for his guidance on some aspects of this paper. He also wants to thank Tim Peterson for his guidance on the use of Groundwater Database for obtaining the groundwater salinity data in the study region. The authors acknowledge the useful comments from two anonymous reviewers that helped improve this paper.

\section{REFERENCES}

Davey, S.M., Baker, P., Frakes, I., and Mullen I. (2006). Opportunities for commercial forestry in Australia. Bureau of Rural Sciences, Australian Government.

Dawes, W.R., Gilfedder, M., Walker, G.R., and Evans, W.R. (2004). Biophysical modelling of catchmentscale surface water and groundwater response to land-use change. Mathematics and Computers in Simulation, 64, 3-12.

Ghassemi, F., Jakeman, A. J., and Nix, H. A. (1995). Salinisation of land and water resources: human causes, extent, management and case studies. University of New South Wales Press Ltd, Sydney, Australia.

Gilfedder, M., Walker, G.R., Dawes, W.R., and Stenson, M.P. (2009). Prioritisation approach for estimating the biophysical impacts of land-use change on stream flow and salt export at a catchment scale. Environmental Modelling and Software, 24, 262-269.

Grayson, R. B., Argent, R. M., Nathan, R. J., McMahon, T. A. and Mein, R. G. (1996). Hydrological recipes: estimation techniques in Australian hydrology. Cooperative Research Centre for Catchment Hydrology, Victoria, Australia. 125pp.

Herczeg, A. L., Dogramaci, S. S., and Leaney, F. W. J. (2001). Origin of dissolved salts in a large, semi-arid groundwater system: Murray Basin, Australia. Marine Freshwater Research, 52, 41-52.

Jarvis A., Reuter, H.I., Nelson, A., and Guevara, E. (2008). Hole-filled seamless SRTM data V4. International Centre for Tropical Agriculture (CIAT), <http://srtm.csi.cgiar.org.>.

van Dijk, A.I.J.M., Gilfedder, M., and Austin, J. (2008). Influence of climate, terrain and land cover on stream salinity in southeastern Australia, and implications for management through reforestation. Hydrological Processes, 22, 3275-3284. 
Malana et al., A top-down approach to understand the effect of vegetation changes on stream salinity

Zhang, L., Hickel, K., Dawes, W.R., Chiew, F.H.S., Western, A.W., and Briggs, P.R. (2004). A rational function approach for estimating mean annual evapotranspiration. Water Resources Research, 40, W02502, doi:10.1029/2003WR002710.

Zhang, L., Dawes, W.R., and Walker, G.R. (1999). Predicting the effect of vegetation changes on catchment average balance. Technical report 99/12, Cooperative Research Centre for Catchment Hydrology, CSIRO Land and Water. 